\title{
COOPERATION
}

\section{Program Life for Africa}

\author{
${ }^{1}$ J osé M Carrera, ${ }^{2}$ Vicenc Cararach, ${ }^{3}$ Asim Kurjak, ${ }^{4}$ Manuel R Carrapato, ${ }^{5}$ Francesc Castella \\ ${ }^{1}$ P resident of Matres Mundi, Barcelona, Spain \\ ${ }^{2}$ Vice President of Matres Mundi, Barcelona, Spain \\ ${ }^{3}$ Vice President of the International Academy of Perinatal Medicine, Zagreb, Croatia \\ ${ }^{4}$ Past President of World Association of Perinatal Medicine, Porto, Portugal \\ ${ }^{5} \mathrm{P}$ ast $\mathrm{P}$ resident of the International Federation of Hospitalary Engineers, Barcelona, Spain
}

Correspondence: J osé M Carrera, Matres Mundi, Londres, 6 p. 8, 08029 Barcelona, Spain, e-mail: jmcarrera@ matres-mundi.org

\section{ABSTRACT}

Life for Africa is an international cooperation program that was developed by Matres Mundi International. It aims to improve the critical situation of maternal and infant health in Africa by improving the number and training of health professionals, particularly in the area of the maternal and infant health. The program, which is sponsored by the majority of the international societies of perinatal medicine (the International Academy of Perinatal Medicine, the World Association of Perinatal Medicine, etc.), consists of the creation of an International School of Perinatal Medicine for Africa and a Reference Hospital for Mothers and Children in Addis Abeba, capital of the African Union. This paper will discuss the reasons in favor of this project and will describe the details and the current situation. It will also provide information about the 'exploratory mission' that several members of Matres Mundi and the international societies made to Addis Abeba.

Keywords: International cooperation, Maternal and infant health, Training of health professionals.

\section{INTRODUCTION}

The A frican continent suffers not only a worrying situation of poverty and scarcity of resources but also a clear difficulty in accessing to the most elemental education. Focusing on the health issue, it is obvious the scant per capita supply of health professionals (doctors, specialists, midwives, nurses, etc.) as well as the high need for hospitals and health centers in decent and el emental conditions of hygiene and public health.

For the time being in A frica, there is only one medical school per 10 million inhabitants, while in Europe the rate is one per 250,000 people. In 11 A frican countries, there are none. And in the others, medical schools are poorly equipped and have scarce resources. For this reason, while in Europe we have a doctor per 350 inhabitants, in the majority of the sub-Saharan countries the rate is 1 doctor per 50,000 inhabitants. The same way, the number of midwives and nurses is too inferior to the acceptable minimum. These facts and the bad socioeconomic situation explain why maternal mortal ity rate $(1,000$ per 100,000 born alive) and perinatal mortality rate (150 per 1,000 born alive) in sub-Saharan countries are the highest in the world.

For these reasons, it is necessary to find strategies to improve the dramatic situation of the maternal and infant health in Africa. ${ }^{1-5}$

\section{MATERNAL AND INFANT HEALTH SITUATION IN AFRICA}

In A frica, each year, around 300,000 women die during pregnancy, delivery or puerperium, as well as 5 millions children under 5 years of age perish. In their majority, the deaths are due to perfectly avoidable causes. The situation in the countries of sub-Saharan A frica is especially bad (Table 1).
Table 1: Situation of health in sub-Saharan Africa

\begin{tabular}{ll}
\hline Life expectancy & 47 years \\
\hline Maternal mortality & $920 / 100,000$ \\
Maternal mortality by abortion & $600 / 100,000$ \\
Neonatal mortality rate & $>45 / 1,000$ \\
Perinatal mortality rate & $160 / 1,000$ \\
Children's mortality rate (under 5 years of age) & $92 / 1,000$ \\
Incidence of HIV & $5.8 \%$ \\
Children's undernourishment & $37 \%$ \\
Teenage pregnancies & $>30 \%$ \\
Hospital beds & $<9 / 10,000$ \\
Deliveries that take place in a health center & $<40 \%$ \\
Doctors (all specialities) & $1 / 50,000$ \\
Annual health care expense per inhabitant & $8 €$ \\
Women with obstetrical fistulae & $2-3$ millions \\
\hline
\end{tabular}

Source: WHO, World Bank, Matres Mundi

To this high mortality, a very high morbidity rate has to be added. For each woman that dies, about ten suffer from serious complications: Genital lacerations, urinary and/or fecal incontinence, pelvic inflammatory disease, genital prolapse, permanent infertility and, above all, urinary fistul a of obstetrical origin. A round two millions A frican women suffer this stigma that permanently jeopardizes their life. ${ }^{6,7}$

No doubt, poverty ( $45 \%$ of A fricans live with less than one dollar a day) and poor economic development in these countries (very low incomes), which, moreover, are in the last positions in the Human Development Index, do explain that dramatic situation. To all this we have to add other factors: Hidden colonialism, bribery, permanent armed conflicts and so on (Table 2). 
Table 2: Socioeconomic situation of sub-Saharan Africa compared with Euro-zone

\begin{tabular}{lll}
\hline & $\begin{array}{l}\text { Sub-Saharan } \\
\text { Africa }\end{array}$ & $\begin{array}{l}\text { Euro- } \\
\text { zone }\end{array}$ \\
\hline $\begin{array}{l}\text { Poverty (less than one } \\
\text { dollar a day) }\end{array}$ & $45 \%$ & $10 \%$ \\
Hunger & $33.4 \%$ & $1.7 \%$ \\
Schooling & $45.7 \%$ & $98.9 \%$ \\
Population growth & $2.3 \%$ & $0.5 \%$ \\
\hline
\end{tabular}

Source: WHO, World Bank

The situation will not change until A frica reaches a minimum sufficient number of health workers, that will allow for right obstetric and pediatric care, and dynamizes health care in its complexity (hygiene, preventive medicine, sexual and reproductive health, etc.). This awful situation of maternal and infant health in A frica will not change by sending equipment, medicines, etc that no one knows how to use. ${ }^{8}$ W hat A frica urgently needs is: D octors, specialists (obstetrics, pediatricians, perineonatologists), midwives, nurses, nutritionists, pediatric nurses, etc. that replace the actual scarce human resources (traditional midwives, nurses with no academic education and so on).

On the contrary, it has not been very useful either to organize courses for empirical or traditional midwives. Using this strategy, maternal mortality not only has decreased, but also in some countries it has increased. That is not the way.

There is unanimity in considering that help to development has to prioritize this aspect, and that the continuous escape of A frican doctors toward developed countries has to be compensated with programs aimed at increasing the number of health workers. ${ }^{9}$

A frica has one hundred times more health problems and relies on one hundred times less heal th professionals, than the necessary. A s a matter of fact, A frica bears $24 \%$ of the global burden of diseases.

M oreover, more than 30,000 doctors and nurses emigrate each year to Europe and America for essentially economic reasons. For this reason, there are more doctors from $B$ enin in France than in B enin itself, and more health professionals from Sierra Leone in Chicago than in Africa. Half of the doctors from A ngola, M ozambique and Liberia work in a OECD country. A frica produces few doctors and loses a major part of them due to emigration. According to the World Health Organization (WHO), among the 57 states of the world that lack doctors and heal th w orkers, 36 are A frican. No doubt, the A frican zone where the situation of maternal and infant health is worst and relies on less resources is the sub-Saharan area.

For this reason, obstetrical care (pregnancy and delivery) often is not in qualified personnel's hands, but rather in empirical midwives, who in general areilliterate and without any academic education. This fact, together with poor hospital resources (most of the regional hospital do not have electricity), difficulties in reaching the hospitals and some anthropological factors (limited tendency to give birth in hospitals), explains such a high mortality rates. ${ }^{10}$

Regrettably, for the time being in A frica, it does not exist a maternal and infant hospital complex whose principal task is the education, training and permanent retraining of health professionals. For this reason, it is necessary a complex found, implemented and organized fundamentally considering these aims.

\section{PROGRAM LIFE FOR AFRICA}

The main objective of the program is to improve the maternal and infant health of Africa, through the training of health professionals (doctors, midwives, nurses, nutritionists, etc.). To reach this basic aim we want to set-up an International School of Perinatal $M$ edicine for $A$ frica that should become a reference for the whole of A frica, and a R eference H ospital for M others and Children.

\section{International School of Perinatal Medicine for Africa}

The International School of Perinatal M edicine for A frica will have three main objectives:

1. To become a center of training in maternal and infant health, to serve as a reference point for the whole continent. This would imply the creation of a medical school on maternal and infant heal th (education of specialists), a medical school of related specialties (ultrasound scan, anesthesia, gynecology, obstetrics and gynecologic surgery, etc.), a school of nursing (midwives, nurses, auxiliary nurses, pediatric nurses, educators of community health) and a school of public health. This task would be the main differential characteristic of the hospital. It would specialize in attending the medicochirurgical problems specific to A frica: M alaria, obstetric fistulae, etc.

2. To do health care research and organization for the whole continent, especially the realization of a 'health map of A frica'. Regrettably, at the moment there are few works on A frica in the medical journals of the various medical specialties. And specifically in the field of maternal and infant medicine, epidemiological and clinical studies are urgently needed. Up to a point, in this sense its mission is similar to the CLA P of M ontevideo of the 70s.

3. To be the residence for teaching staff and for scholars from the whole A frica.

The International School of Perinatal M edicine would have the installations and resources necessary to carry out its educational mission. In this sense it ought to have the following:

1. Educative units, independent from the hospital structure, but close to it, and connected with it. They will be equipped with:

- Auditorium

- Classroom complex (six classrooms with different capacities) 
- Library

- A dministration area

Each of these areas is to have all necessary equipment for teaching and working.

2. Research area (reprography, computering and telecommunications room, etc.)

Training will be given by a permanent (local and international) teaching staff selected by $M$ atres $M$ undi, and teaching staffs provided by the International Scientific A ssociations to carry out time-limited specific courses (perinatal medicine, fetal medicine, obstetric-gynecologic ultrasound scan, obstetric-gynecologic surgery, etc.). To reach this goal, the hospital is to be the permanent A frican headquarter of the various I nternational Scientific A ssociations that will establish in it permanent schools of the various specialities.

The collaboration with Addis A beba University is fundamental to achieve these expectancies.

The international school would collaborate with the university in:

1. The education of the future doctors (the university will fix its requirements)

2. The training of specialists in perinatal medicine (obstetricians and pediatricians) as well as midwives and specialized nurses (pediatrics, nutrition, etc.).

The degrees and/or qualifications the center will confer would be guaranteed by A ddis A beba U niversity and the various international scientific associations.

The International School of Perinatal M edicine for A frica would have the appropriate medical technology to facilitate the learning and education of the various specialities.

The scholars, from the various A frican countries, would gain entrance to the project through an appropriate selection and would have to sign an agreement by which they commit themsel ves to work in A frican heal th centers at least during the lapse of five years following their education period.

The program of the various courses shall be developed by the international societies with the agreement of the local university authorities.

Representatives of several International Scientific Societies of Perinatal M edicine will be part of the 'scientific committee' of the center.

Once the construction of the international school will be completed, it will be set in motion directed and managed for an indefinite period by $\mathrm{M}$ atres $\mathrm{M}$ undi, as the representative of the above-mentioned scientific societies.

\section{Courses}

- M aternal and perinatal mortality

- Neonatal assessment

- Perinatal nursing care

- Obstetrical operations

- Pregnancy-related abnormalities

- Prenatal diagnosis

- Pediatric cardiology
- Pediatric dermatology

- A nalgo-anesthesia in perinatology

- Sexually transmitted illness

- Family planning

- M edical laboratory technology

- Perinatal nutrition

- Reproductive health

- Pediatric infectious diseases

- Obstetric ultrasonography

- Perinatal ultrasonography

- Emergencies in perinatal medicine

- Doppler in perinatal medicine

- Screening in perinatal medicine

- Preterm delivery

- Fetal monitoring

- Multiple pregnancy

- Labor and delivery

- M aternal diseases

- Obstetric fistulas.

\section{Reference Hospital for Mothers and Children}

The reference hospital will consist of a maternity hospital with services on obstetric, pediatrics, gynecology, internal medicine and a nutritional center capable to meet the needs, in terms of maternal and infant health, of a large geographical area with little heal th equipment, whose function will not be only assistant, but mainly educational for the whole continent. This would probably imply the foundation and/or restoration of health centers, or peripheral consulting units, dependent on the hospital.

To carry out its educational mission, the hospital should have a minimum of 150 beds and have available all fundamental services: Delivery room, general surgical block, infirmary, intensive care unit, day hospital, emergencies, consulting rooms, diagnosis services 4 (kitchen, laundry, etc.) (Table 3 ).

The team responsible for the project and planning (architects and engineers) is to be managed by an expert consultant on hospital-related subjects, he will create a technical secretariat

Table 3: Total area of the hospital

Areas of the various units

Hospitalization facilities

Outpatient services

Surgical wing

Main diagnosis center

Support units

General services

Teaching unit

Dormitories for health staff

Total

$1,276 \mathrm{~m}^{2}$ $880 \mathrm{~m}^{2}$

$950 \mathrm{~m}^{2}$

$521 \mathrm{~m}^{2}$

$246 \mathrm{~m}^{2}$

$923 \mathrm{~m}^{2}$

$803 \mathrm{~m}^{2}$

$500 \mathrm{~m}^{2}$

Traffic areas

$6,049 \mathrm{~m}^{2}$

Internal (corridors),

general (halls, corridors...)

and accesses

Space for future expansions

$1,000 \mathrm{~m}^{2}$

Total area

$10,103 \mathrm{~m}^{2}$ 
to coordinate all involved teams. A hospital will have a modular structure that permits a growth without problems. ${ }^{10}$

The hospital is to have a limited permanent staff (doctors, nurses, midwives, administrative personnel, etc.), but a much larger complementary staff, composed of external volunteers, and a staff in training practice from various A frican countries.

The total constructed surface will be $11,000 \mathrm{~m}^{2}$. The hospital will be constructed on building land of $20,000 \mathrm{~m}^{2}$, conceded by the Ethiopian government.

\section{Chosen Location}

A fter having studied several possibilities to establish the program A ddis A beba (E thiopia) was chosen, since it fulfills all the conditions and, besides, now it is the capital of the A frican Union. The choice was also made because of the political stability of Ethiopia.

Ethiopia is one of the sub-Saharan countries with more heal th problems and less resources to face them (see Table 4). Like most of the countries of the region, it has to cope with a large emigration of its heal th personnel toward N orth A merica and Europe. It is estimated that there are more Ethiopian doctors in Washington (USA) than in Ethiopia itself.

On the contrary, besides fulfilling all the conditions mentioned in section 3.1, it offers several additional advantages in comparison with the surrounding countries: Absence of religious fundamentalism (62\% of orthodox Christians), multiples ethnic groups (O romo, A mhara, Tigray, Sidama, etc.) that coexist peacefully, and the end of the separatist war of E ritrea, once this territory obtained independence.

Ethiopia is also one of the founding members of the socalled common market for Eastern and Southern A sia (COMESA) as well as of the intergovernmental authority in development (IGAD).

Table 4: Health situation in Ethiopia

\begin{tabular}{ll} 
A. Resources & \\
Medical schools & 6 \\
Hospitals & 149 \\
Health centers & 732 \\
Help centers & 11,446 \\
Private clinics & 1,788 \\
Nonprofitmaking private clinics & 271 \\
Pharmacies & 320 \\
Drug shops & 577 \\
Rural sale posts of medicines & 2121 \\
One hospital room per inhabitants & 4,900 \\
Annual health care expense per inhabitant & $3.8 €$ \\
B. Indexes & \\
Life expectancy & 45 years \\
Maternal mortality rate & $1,000 /$ \\
& 100,000 \\
Children's mortality rate (under 5 years of age) & $140 / 1,000$ \\
Immunized children & $20 \%$ \\
Incidence of HIV/AIDS & $4.4 \%$ \\
Children and woman & 6.2 \\
\hline
\end{tabular}

Source: World Bank, WHO
During J une this year, A ddis A beba will be the venue of the first congress of the 'A frican A ssociation of Perinatal M edicine', founded in Barcelona in 2010, with the sponsorship of $M$ atres $M$ undi International together with several International scientific societies, especially W A PM and IAPM.

Ethiopia has acceptable land, sea (through Djibouti) and air (22 companies operate in its capital's airport) communications, with direct flights to 40 A frican, European and A sian cities. B esides, we also enjoy appropriate political and medical contacts with the country.

\section{Dependence}

The International School of Perinatal M edicine for A frica is to be directed and administered by $M$ atres $M$ undi and the International Societies of Perinatal M edicine, under the control and the collaboration of the Ethiopian government.

As a matter of fact, the school will be the African 'headquarter' of M atres M undi, the International A cademy of Perinatal Medicine (IAPM) and several other International Societies.

A joint venture will be created by the International A ssociations of Perinatal Medicine (World A ssociation of Perinatal Medicine (WAPM), International A cademy of Perinatal M edicine (IA PM ), European A ssociation of Perinatal M edicine (EA PM), etc.), with the state and local governments and the academic authorities of the country.

This will allow the establishment of permanent schools of Perinatal Medicine (managed by WAPM), Fetal Medicine (managed by the International Society "The Fetus as a Patient") and $O$ bstetric and Gynecologic U Itrasound Scan (managed by Ian D onald School). The school will al so be the headquarter of these international institutions in A frica.

Once the construction of the 'R eference Hospital of M others and Children' will be completed, it will form part of the national health system of Ethiopia.

\section{Financial Resources}

Matres $M$ undi prioritizes this project above all others, be in A frica or in Latin A merica, to concentrate al most completely on this subject. Fund-raising will only focus on this project.

$M$ atres $M$ undi will try to obtain funding from:

- Official subventions of several countries

- Private foundations and social investors with solidarity values

- Scientific societies that will mostly contribute with professionals (courses, etc.)

- Personnel of Spanish solidarity maternities that should not only provide mainly volunteers, but also economic contributions.

- Technological and pharmaceutical companies that would participate furnishing equipment and laboratory supplies

- Professional associations (midwives, nurses, etc.) that would contribute with volunteers and organization

- Business schools that should al so collaborate in training on international school and hospital administration. 
The undergraduate programs (special izations in obstetrics, pediatrics or perinatal medicine, etc.) and the postgraduate courses will have a registration fee cal culated according to the economic situation of A frica. Furthermore, the center will establish scholarships and will try to get the African and multinational companies and enterprises to defray these expenses.

\section{Promoters of the Project}

The NGO M atres M undi is the main promoter of the project. The local collaborator entity is cielo foundation.

The project will be formul ated and carried out, thanks to its basic infrastructure (central headquarters, administrative structure, management area, communications area, international relations area, etc.), together with its human resources (volunteers, workers, etc.).

A s it is known, M atres M undi is a NGO on development with 17 years of experience, whose fundamental aim is the improvement of maternal and infant health all over the world. It was founded and it is managed by maternal and infant heal th professionals (obstetricians, pediatricians, neonatologists, midwives, nurses, etc.). Up to today it has carried out more than 300 projects of cooperation in the maternal and infantfield, in African (Democratic Republic of Congo, Rwanda, M ozambique, etc.), L atin A merican (Peru, B olivia, Nicaragua, etc.) and A sian (Philippines) countries. From an international perspective, it is the solidarity agency of most of the Associations or Scientific Societies of Perinatal Medicine (WAPM , EAPM ; IAPM, Ian Donald School, The Fetus as a Patient, etc.).

In September 2010, in B arcelona, it organized the 'First Global Congress of M aternal and Infant Health', attended by delegations from 127 countries with a total of 2000 delegates and global experts. During this event, two scientific continental associations of perinatal medicine were formed: The A frican A ssociation of Perinatal Medicines (AAPM) and the Latin A merican Federation of Perinatal M edicine (FLA M P). At the same time this project was presented, the ceremony being attended by all the presidents of the national and international perineonatological associations.

For the realization of this project, an international foundation will be created, whose specific aims will be fund-raising for its realization, establishment of an appropriate management structure, capable of planning and caring out the project and laying the foundations for its sustainability in the future. The foundation, called 'Life for Africa', will be structured in a council, an honor committee, a scientific committee and an advisory committee. Prestigious personalities of international importance will participate in these bodies as well as the presidents of the international scientific societies that sponsor the project. A t the moment, the necessary steps to internationally register this foundation are being taken.

The project relies on the patronage and collaboration of all the International Scientific Societies of Perinatal Medicine, especially of the WA PM , IA PM, the international society 'The Fetus as a patient' and 'I In D onald School of U Itrasonography' as well as on the valuable auspices of the World Health Organization (W HO).

\section{Expected Results}

Through the programming of academic activities elaborated by $M$ atres $M$ undi with the help of several international scientific societies, it is expected to achieve the following immediate results:

1. A nnual graduation of 50 to 60 special ists in obstetrics and perinatal medicine

2. A nnual graduation of 50 to 60 specialists in pediatrics and perinatal medicine

3. A nnual graduation of 100 academic midwives.

4. Production of 40 annual postgraduate courses about specialties related to perinatal medicine (ultrasonography, emergencies in perinatal medicine, fetal monitoring, obstetric fistulas, perinatal nutrition, etc.); as a whole, the trainees will be 1800 per year.

The medium/long-term objective is to reduce the high numbers of maternal, perinatal and infant mortality in A frica. Thanks to the action of these new professionals of the maternal and infant health.

\section{EXPLORATORY MISSION TO ADDIS ABEBA}

In early M ay 2010, M atres M undi organized an exploratory expedition to $A$ ddis $A$ beba in order to confirm whether the city was a suitable location to establish the International School of Perinatal M edicine for A frica and to construct the Reference Hospital of M others and Children.

The expedition involved two representatives from $M$ atres Mundi (José M Carrera and Vicenç Cararach) two representatives from the International Societies of Perinatal M edicine (Prof A sim K urjak and M anuel R C arrapato) and the coordinator of the team of architects and engineers who are planning both projects (Francesc C astella).

Our hosts were representatives from the Cielo Foundation (M rs A na Picazo and local contributors), an organization that is helping us with the hospital project.

During five days, we met with the local authorities who are involved in the project: Ethiopia's Health M inister (Hon. Teodoros A dhanom Ghebreyesus), the Dean of the Faculty of $M$ edicine in A ddis A beba (Prof Dereje Gulelat) and the Director of the School of Nursing of the Faculty of M edicine in A ddis A beba (Prof A srat Demessie). Professor B ogale W orku, H ead of Pediatrics in A ddis A beba, accompanied us to these meetings. Professor B ogale was not only our defender before government representatives, but was also one of the people who was most passionate about the project since, at present, there is not a single maternity and infant hospital in the whole country.

Professor B ogale W orku accompanied us to the teaching hospital of the Faculty of Medicine as well as to other 


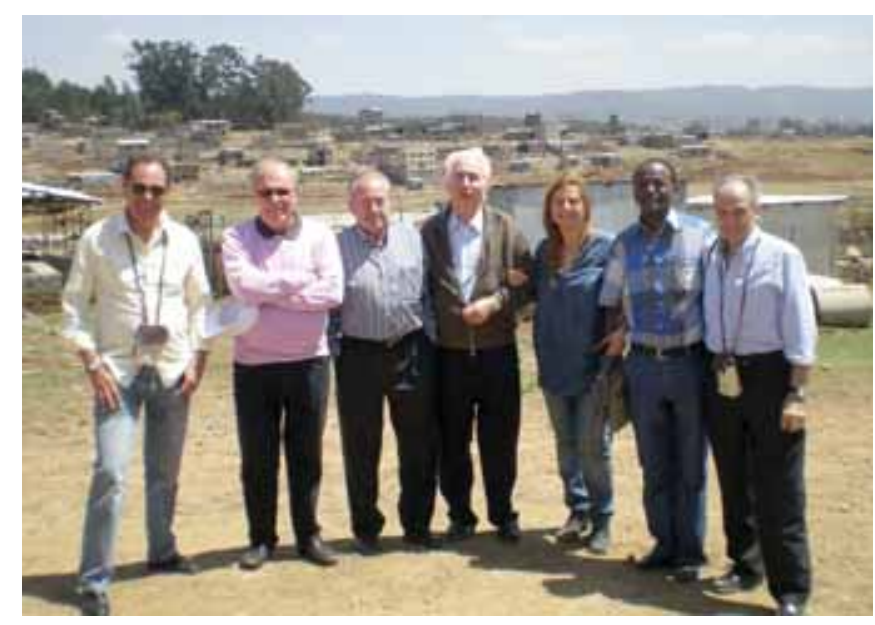

Components of exploratory mission to Addis Abeba

smaller hospitals. We also had the opportunity to visit the facilities of two SpanishNGOs, 'Cielo 133' and 'G lobal Infancia'.

Lastly, we had a meeting with M rs M aria Cruz Ciria M atilla from the Addis A beba office of the Spanish A gency for International Development Cooperation and with the A mbassador of Spain.

We were able to visit the plot of land that has been al located to us. The engineer, $\mathrm{Mr}$ Frances Castella, considers both the dimensions $\left(20,000 \mathrm{~m}^{2}\right)$ and location to be suitable for our projects. The local architect (M r Y ibrah M ehari) and several representatives from Cielo 133 accompanied us to the site.

This project is within the current line of work of cooperation for autonomous devel opment, which aims to create sustainable change by ensuring that the work can be continued by governments and local organizations in the future.

\section{REFERENCES}

1. U nited Nations. M illenium Project. Project tak force on Child Health and Maternal Health. New Y ork Un. Development Program 2005 SA RTOIB J: Creating a sustainable clinic. IFHE, Digest 2011;1-4.

2. WHO/Regional office for Africa: Reducing maternal deaths challenge of the new millenium in the A frican region. Statement. B razewille 2006.

3. WHO. Pregnancy, childbirth, postpartum and newbon care: A guide for essential practice. G eneve 2006.

4. WHO. World Heal th Report 2005: M ake every mother and child count Geneve, 2005.

5. Matres Mundi: M aternal and Infant Health in the World. Barcelona 2006.

6. The A frican Unim Commission: Plan of action on service and reproductive health and rights, $M$ aputo, Sept 2006;18-22.

7. Carrera JM, Devesa N, Chacón D, Cararach V, Fabre E, Foradada CM , et al. R ecommendations to diminish the maternal mortality. J Perinat M ed 2007;35:266-77.

8. Carrera J M. O bstetric ultrasounds in A frica: Is it necessary to promote their appropriate use? Donald School Journal of Ultrasound in Obstetrics and Gynecology. April-July 2011;5(2):79-84.

9. Benagiano G, Thomas B. Developing countries: The goals of safe motherhood in: "Textbook of Perinatal M edicine" (2nd ed): Kurjak A, Cheverna FA (Eds), Informa Health Care, London 2006;2135-45.

10. M atres M undi WAPM : Recommendations and Guidelines for Perinatal M edicine, Barcelona 2007. 